\title{
Inferring the diversification of the epiphytic fern genus Serpocaulon (Polypodiaceae) in South America using chloroplast sequences and amplified fragment length polymorphisms
}

\author{
H.-P. Kreier $\cdot$ M. Rex $\cdot$ K. Weising $\cdot$ M. Kessler $\cdot$ \\ A. R. Smith · H. Schneider
}

Received: 25 July 2007/ Accepted: 28 January 2008/Published online: 15 May 2008

(C) The Author(s) 2008

\begin{abstract}
In this study, we infer the phylogeny of the recently described epiphytic fern genus Serpocaulon. Four regions of the plastid genome were sequenced for 68 samples, representing 31 of ca. 40 currently accepted species of this genus. The reconstructed phylogeny supports most of the previously proposed clades, but more exhaustive studies are needed to improve species delimitation in several terminal clades. A further objective of this study was to determine the utility of amplified fragment length polymorphism (AFLP) data to study the diversification of species complexes. Independent analyses of data sets based on chloroplast DNA sequences or AFLPs resulted in phylogenetic trees with similar topologies, but showed also some notable differences. We present an explicit hypothesis of the biogeographic history of Serpocaulon. All reconstructed phylogenies suggest an origin of this genus in the Bolivian-Brazilian region and indicate a
\end{abstract}

H.-P.Kreier · M. Kessler · H. Schneider

Albrecht-von-Haller Institute of Plant Sciences,

Georg-August University Goettingen, Untere Karspüle 2,

37073 Göttingen, Germany

M. Rex $\cdot$ K. Weising

Plant Molecular Systematics, Institute of Biology,

Department of Sciences, University of Kassel,

Heinrich-Plett Str. 40, 34132 Kassel, Germany

A. R. Smith

University Herbarium, 1001 Life Sciences Building,

University of California, Berkeley, CA 94720-2645, USA

H. Schneider $(\bowtie)$

Department of Botany, Natural History Museum,

Cromwell Road, London SW 7 5BD, UK

e-mail: h.schneider@nhm.ac.uk major role of the Bolivian Andes as a stepping-stone in the colonization of northern regions of the Andes. The majority of the extant species diversity of this almost exclusively epiphytic fern clade is likely the result of an adaptive radiation that was triggered by the colonization of Andean mountain forest habitats (above 2,000 m). This is the first report of a Bolivian origin of fern diversification in Andean mountain habitats using phylogenetic evidence.

Keywords Arbitrarily amplified dominant markers . Andean radiation - Bolivia $\cdot$ cpDNA phylogeny · Polypodiaceae $\cdot$ Serpocaulon

\section{Introduction}

South America is known for its enormous richness in plant and animal species. The tropical parts of the Andes alone contain an estimated number of 45,000 indigenous vascular plant species, of which 20,000 (44\%) are endemics (Myers et al. 2000). No other tropical mountain range displays such a high biodiversity (Smith and Cleef 1988), and ferns are no exception to this rule (Tryon 1972, 1985, 1986). The high proportion of temperate genera among the Andean flora suggests that a significant number of taxa originated through colonization and/or radiation of species that were pre-adapted to low temperatures in the rising mountains (Vuilleumier 1970; Hughes and Eastwood 2006). Several such radiations have been studied in the páramos, isolated patches of land above the treeline, where the level of endemism can reach 60\% (Luteyn et al. 1999). DNA sequences and phylogenetic approaches have been employed in increasing detail to reconstruct the historical biogeographic patterns creating the diversity of plants found in the Andes. The majority of these studies have 
focused on angiosperms such as Valerianaceae (Bell and Donoghue 2005), Asteraceae (Cuatrecasas 1986; Monasterio and Sarmiento 1991; Rauscher 2002), and Gentianaceae (von Hagen and Kadereit 2001, 2003), whereas only one study has so far been devoted to ferns. Sánchez-Baracaldo (2004) investigated the biogeography of the Jamesonia Hook. \& Grev. plus Eriosorus Fée complex, a group of terrestrial ferns of which a substantial number of species occurs in páramos.

Evidence for radiations in the Andean montane forests has been less well explored, even though correlations between species diversity and the rise of the Andes have been proposed for several epiphytic vascular plant groups. So far, only the epiphytic homosporous lycophyte genus Huperzia L. has been investigated using a molecular phylogenetic approach (Wikström et al. 1999). Other candidates for similar studies are two mainly epiphytic fern genera belonging to the derived fern family Polypodiaceae: Campyloneurum C. Presl. (León 1992) and Serpocaulon A. R. Sm. (Smith et al. 2006). The latter genus comprises ca. 40 species recently segregated from Polypodium L. (Smith et al. 2006). Serpocaulon is part of a predominantly neotropical clade that also includes Campyloneurum, Microgramma C. Presl, Niphidium J. Sm., as well as the grammitid ferns (Schneider et al. 2004b).

The monophyly of a clade containing 22 Serpocaulon species was strongly supported in previous analyses based on sequences of four chloroplast genome regions (cpDNA; Schneider et al. 2004b; Smith et al. 2006). Morphologically, the genus is characterized by a combination of goniophlebioid venation, usually long-creeping cord-like rhizomes, and at least partially clathrate scales (Smith et al. 2006). Unraveling the infrageneric phylogeny of Serpocaulon proved difficult, due to limited variation recovered in chloroplast sequences and frequent homoplasy in its morphology. However, several trends in the morphological evolution of Serpocaulon were suggested, such as the reduction in rhizome diameter, reduction of scale number and size, and increasing dissection of the lamina. Serpocaulon species that occupy the lowermost branches of the phylogenetic tree preferentially occur at low elevations, while those species that take more derived positions tend to grow in the middle to higher elevation of Andean habitats (Smith et al. 2006). This pattern is compatible with the hypothesis of an origin of Serpocaulon outside the Andes followed by colonization to and subsequent adaptive radiation in this mountain chain. Several informal groups were proposed by considering DNA nucleotide variation and morphology, but it was concluded that improved taxonomic sampling and the use of more sensitive markers would be required for a more comprehensive understanding of the evolutionary history of Serpocaulon. In the present study, we extend the taxonomic sampling of the chloroplast DNA sequence data set and also explore the utility of amplified fragment length polymorphisms (AFLP) for revealing information about fern relationships among closely related species and within species.

AFLPs are among the most frequently used anonymous dominant markers, because they are applicable to all organisms without requiring sequence information and provide well-reproducible, highly variable multi-locus phenotypes (reviewed by Bussell et al. 2005). It is generally assumed that polymorphisms visualized by AFLP bands are more or less randomly distributed across the genome. Phylogenetic trees based on AFLPs are thus more likely to reflect a species tree, whereas gene trees are produced in studies using sequences of single genes. AFLPs are preferentially applied at the intraspecific level, but are also useful in studying relationships among closely related species where other markers fail to display sufficient variation (Hodkinson et al. 2000; Després et al. 2002; Koopman et al. 2001; Zhang et al. 2001; Pelser et al. 2003; Koopman 2005). Relatively few studies have employed AFLPs to study intra- or interspecific relationships of ferns, namely Asplenium hookerianum Colenso and A. colensoi Colenso (Perrie and Brownsey 2005), Athyrium distentifolium Tausch ex Opiz (Woodhead et al. 2005), Polystichum spp. (Perrie et al. 2003), and Sticherus flabellatus R. Br. (Keiper and McConchie 2000). Besides AFLPs, other molecular markers, e.g., microsatellites and RFLPs, have been used to study Adiantum capillus-veneris L. (Pryor et al. 2001), Adiantum reniforme L. var. sinense Y. X. Lin (Kang et al. 2006), Athyrium distentifolium (Squirrell et al. 2004) and Marsilea strigosa Willd. (Vitalis et al. 2001, 2002). Most of these studies employed anonymous markers without comparison with evidence provided by DNA sequence data, which is the approach in our study.

The objective of this paper is to revise and expand our knowledge of the infrageneric phylogeny of Serpocaulon beyond what has previously been presented (Smith et al. 2006). Our extended sampling now includes 31 out of a total of ca. 40 species. Moreover, we included multiple samples from species with variable morphology and/or wide distribution ranges such as $S$. crystalloneuron, $S$. fraxinifolium, S. latipes, S. sessilifolium and S. triseriale. Finally, we explore the utility of independent or combined analyses of AFLP and cpDNA data sets to infer the evolution of epiphytic fern diversity. Based on the expanded sampling of markers and taxa, we re-evaluate previously suggested hypotheses concerning the biogeographic history of the genus, especially the correlation between its adaptive radiation and the rise of the Andes. 


\section{Materials and methods}

Plant material, DNA isolation and data set assembly

Dry leaf material was stored in silicagel. DNA was extracted using the Invisorb Spin Plant Mini Kit (Invitek, Berlin, Germany) following the manufacturer's protocol. Voucher information and GenBank accession numbers for all specimens used in this study are given in Table 1. The full chloroplast data set (in the following referred to as "large data set") comprises 68 samples from 31 Serpocaulon species and six outgroup samples. One representative each of several groups suggested to be closely affiliated with Serpocaulon were used as outgroup, i.e., Campyloneurum [C. brevifolium (Lodd. ex Link) Link], Microgramma [M. mauritiana (Willd.) Tardieu], Niphidium $[N$. nidulare (Rosenst.) Lellinger], Pleopeltis [P. bombycina (Maxon) A. R. Sm.], Polypodium s.str. $[P$. vulgare L.], and the grammitid ferns [Adenophorus oahuensis (Copel.) L. E. Bishop]. A subset of this data set, consisting solely of Serpocaulon species, was selected for exploring the utility of AFLP data. Serpocaulon triseriale was selected as the outgroup taxon in this small data set. Corresponding AFLP and cpDNA data sets ("small data set") were combined (total evidence approach) and independently analyzed and the results subsequently compared.

\section{Chloroplast sequences (cpDNA)}

Sequences of four chloroplast DNA regions, i.e., $r b c \mathrm{~L}$, $r p s 4, r p s 4-t r n S$ intergenic spacer (IGS) and $t r n \mathrm{~L}-\mathrm{F}$ IGS were generated using PCR primers and protocols as described in previous studies (Haufler and Ranker 1995; Schneider et al. 2002, 2004a, 2004b; Haufler et al. 2003; Janssen and Schneider 2005). All new sequences were generated using DYEnamic ET Primer DNA Sequencing Reagent (Amersham Biosciences, UK) and run out on a MegaBACE 100 capillary sequencer. Some sequences used in this study have been published in previous papers (Schneider et al. 2004a, 2004b; Smith et al. 2006). All cpDNA sequences were aligned manually using MacClade 4.0 (Maddison and Maddison 2000). Ambiguously aligned regions were excluded from all analyses. Simple indel coding was executed to retrieve the phylogenetic information given by absence/presence of putatively apomorphic indels in the non-coding cpDNA regions. Phylogenetic analyses were performed with and without including indels and checked carefully for conflicting signals in the indel data set. No evidence was found for independent gain of indels in the studied cpDNA regions.
AFLP assays

AFLP data were generated according to the protocols of Debener and Mattiesch (1999) and Rex et al. (2007), with some modifications. In the first step, about $250 \mathrm{ng}$ of genomic DNA from each of 33 Serpocaulon samples were double digested in a final volume of $25 \mu \mathrm{L}$ with $M s e \mathrm{I}$ and HindIII, and ligated to HindIII and MseI adapters in the same reaction. After incubation at $37^{\circ} \mathrm{C}$ for $15 \mathrm{~h}$, the assays were heated to $65^{\circ} \mathrm{C}$ for $20 \mathrm{~min}$ to deactivate the enzymes. Two consecutive PCR amplifications were then carried out, with primers containing either one $(+1)$, three $(+3)$ or four $(+4)$ selective nucleotides at their $3^{\prime}$ ends (Table 2). Polymerase chain reactions (PCRs) were performed in a Biometra T-Gradient Cycler (Biometra, Göttingen, Germany) or a Bio-Rad i-Cycler (Bio-Rad Laboratories, Munich, Germany). Reaction assays and cycling protocols were adopted from Rex et al. (2007). In the first (preamplification) PCR, $5 \mu \mathrm{L}$ of the restriction-ligation assay was used as a template, and MseI $+\mathrm{C}$ and HindIII + A served as pre-selective primers. Selective amplification assays were then performed using $2.5 \mu \mathrm{L}$ of a 1:30 diluted pre-amplification mixture as a template and various combinations of $\mathrm{MseI}+3(\mathrm{or}+4)$ primer (unlabeled) and HindIII +3 (or +4$)$ primer (fluorescence-labeled with IRDye700 or IRDye800; MWG Biotech, Ebersberg, Germany). The differential labeling with two fluorochromes allowed us to multiplex two sets of AFLP products in the same reaction. The final products of each selective PCR were mixed with 1 volume of loading buffer containing $98 \%$ (v/v) formamide and denatured at $80^{\circ} \mathrm{C}$ for $5 \mathrm{~min}$. Aliquots of $0.5 \mu \mathrm{L}$ from each sample were then electrophoresed on denaturating $41 \mathrm{~cm} \times 0.2 \mathrm{~mm}$ polyacrylamide gels [6\% Sequagel XR (National Diagnostics, Atlanta) in 1× TBE buffer (Sambrook and Russell (2001)], using an automated sequencer (Li-Cor 4200 IR2, Li-Cor Inc., Lincoln, NE). Fragment mobility was measured by real-time laser scanning. Gel images were stored electronically. AFLP banding patterns were evaluated manually, by assigning to each band in a particular position one of three states: present (1), absent (0), or uncertain. Only bands that were unequivocally interpretable as either present or absent were assembled to generate a binary (1/0) matrix. Principal coordinate analyses using the software package MVSP (Kovach Computing, Pentraeth, UK) were performed for the complete AFLP data set, as well as for different subsets to estimate the randomness of the fragment distribution. MacClade was also used to assemble a binary matrix resembling the absence/presence of AFLP bands for analyses using software programs mentioned below. 


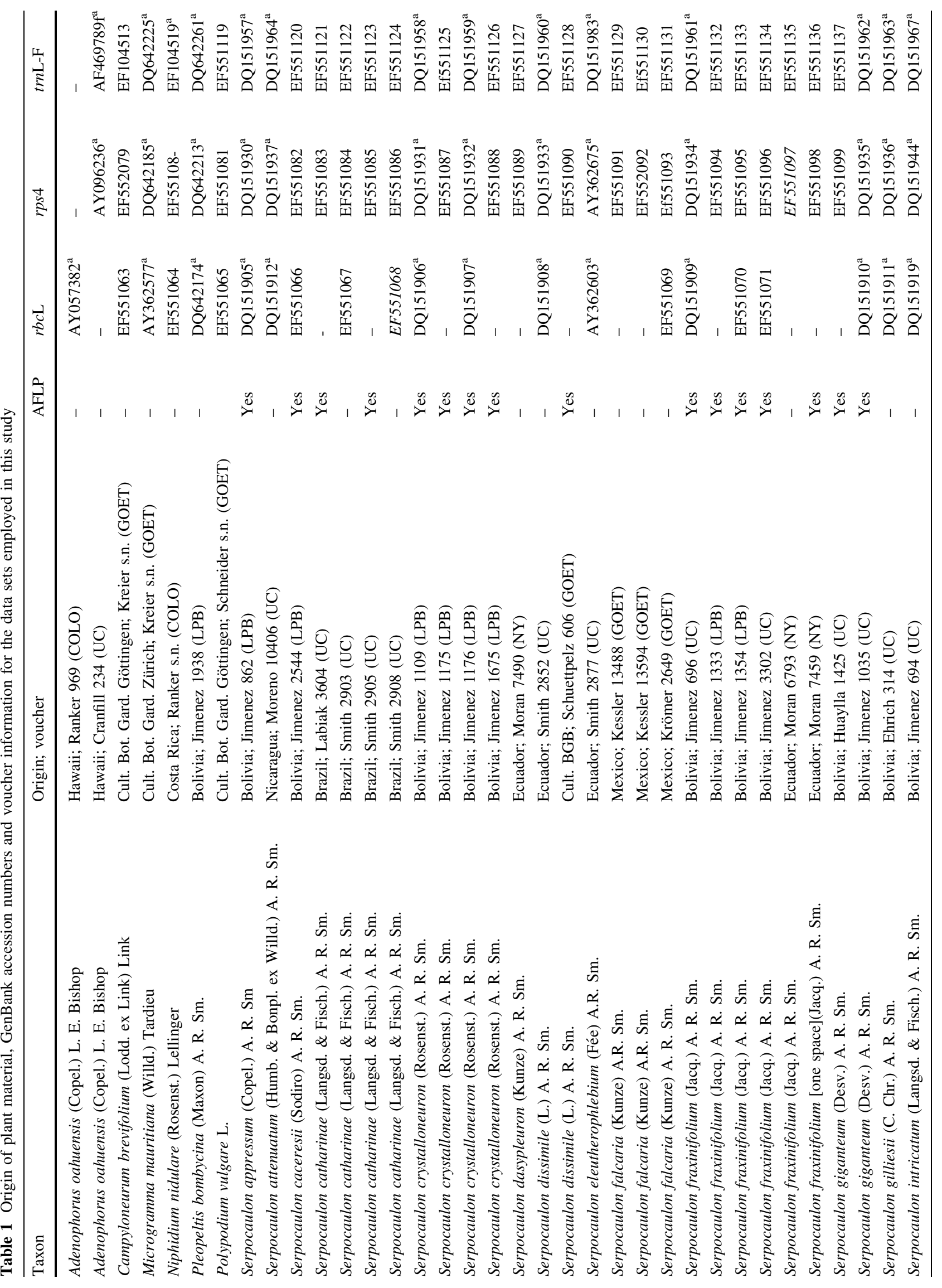




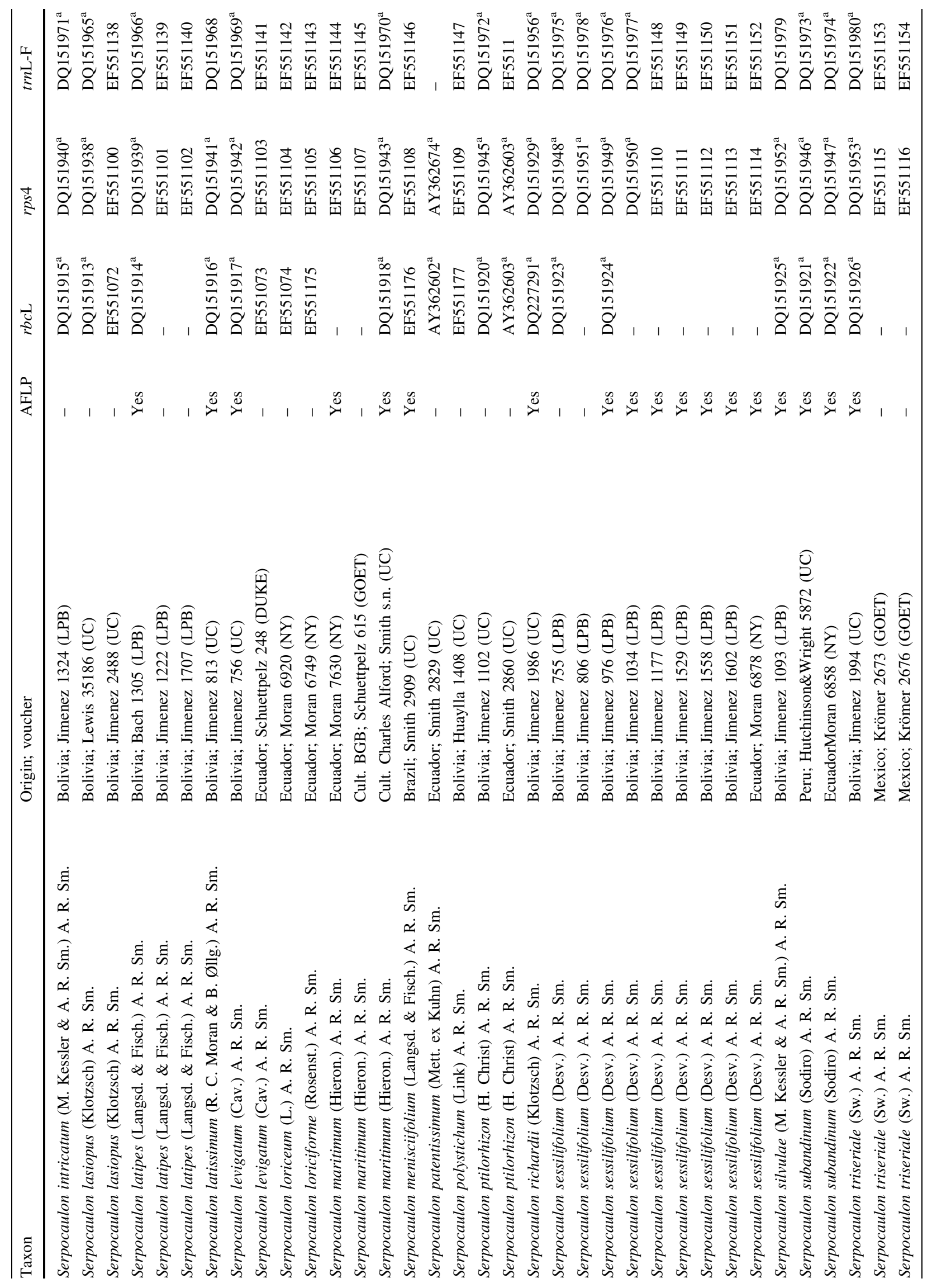




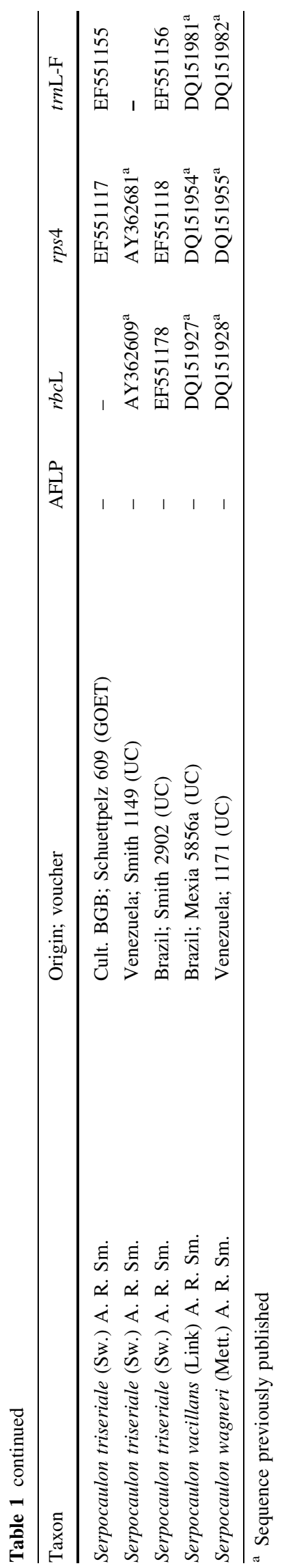

Phylogenetic analyses

Phylogenetic analyses of the chloroplast sequence data were performed using PAUP* 4.0b10 (Swofford 2000) and the software tool GARLI 0.951 (Zwickl 2006). Chloroplast sequence data were analyzed using maximum parsimony (MP) and maximum likelihood (ML) analyses. MP analyses were performed using PAUP as heuristic searches with 100 random starting trees, and TBR branch swapping to completion. Maximum parsimony bootstrap analyses (MPBS) were executed with 1,000 bootstrap replicates, each with 10 random starting trees and TBR. ML analyses were executed with GARLI 0.951, implementing the GTR model and parameters as determined using the software Modeltest (Posada and Crandall 1998). Search parameters were specified according to program defaults. Non-parametric bootstrap values for the maximum likelihood analyses (ML-BS) were calculated with 100 bootstrap replicates using GARLI. AFLP character matrices were analyzed either directly by carrying out maximum parsimony analyses as described above for cpDNA, or by transforming them at first into a Nei-Li distance matrix and reconstructing a neighbor-joining (NJ) tree using PAUP (not shown). The software SplitsTree 4.0 (Huson and Bryant 2006) was employed to infer the relationships indicated by the Nei-Li distance matrix more rigorously using the NeighborNet algorithm (Bryant and Moulton 2002). A single sample of $S$. triseriale was used as an outgroup taxon in the MP analyses of the AFLP data. Total evidence analyses were performed using the maximum parsimony algorithm as implemented in PAUP. All characters were treated as equally weighted. The total evidence data set comprises the cpDNA sequences, AFLP bands and the absence/presence of putative apomorphic indels in the cpDNA non-coding regions.

Reconstructing the biogeographic history

To infer the biogeographic history, ancestral distributions were reconstructed using maximum parsimony and maximum likelihood as described previously (Kreier and Schneider 2006). These analyses were performed using MacClade (Maddison and Maddison 2000) and Mesquite (Maddison and Maddison 2004). In the first step, we reconstructed ancestral distributions using the phylogram obtained in the ML analyses of the large data set, and using the country in which the sample was collected as the character state. To overcome the limits of the available taxonomic sampling, the phylogenetic hypothesis was simplified by using a single terminal unit as a representative for each monophyletic species. Species complexes such as $S$. crystalloneuron were treated as a single terminal unit. Polyphyletic species such as $S$. levigatum were 
Table 2 Primer combinations used in the AFLP analysis

\begin{tabular}{lll}
\hline Preamplification & Amplification & Total bands \\
\hline MseC-HindA & MseCAA-HindATAG & 29 \\
MseC-HindA & MseCAA-HindATCT & 28 \\
MseC-HindA & MseCAC-HindACA & 7 \\
MseC-HindA & MseCAC-HindAGC & 22 \\
MseC-HindA & MseCATC-HindATAG & 28 \\
MseC-HindA & MseCATC-HindATCT & 21 \\
MseC-HindA & MseCTA-HindACCG & 54 \\
MseC-HindA & MseCTA-HindACTC & 60 \\
MseC-HindA & MseCTCA-HindACCG & 34 \\
MseC-HindA & MseCTCA-HindACTC & 29 \\
\hline
\end{tabular}

handled as two or more terminal units. For each terminal unit, the known distribution was scored with the following, selected areas of putative endemism: Brazil, Bolivia, Central Andes (including Peru, Ecuador, Colombia), northern Andes to southern Central America (Venezuela, Panama, Costa Rica), northern Central America (El Salvador to Mexico) and the Caribbean. We also explored elevational aspects by scoring taxa as either predominantly occurring above or below $1,500 \mathrm{~m}$.

\section{Results}

\section{Chloroplast sequences (large data set)}

Maximum likelihood analysis of the large data set yielded an optimal tree with $-\operatorname{lnL}=10,306.35136$ (Fig. 1). Maximum parsimony analysis of the same data set resulted in 21,000 most parsimonious trees with a length of 907 steps, consistency index of 0.6759 , homoplasy index of 0.3241 , retention index of 0.7544 and a rescaled consistency index of 0.5099 (Fig. 2). The bootstrap values were generally low. Both ML and MP analysis found basically the same topology, except for several polytomies in the maximum parsimony consensus tree. Altogether, the ingroup taxa can be divided into nine clades, which are arranged in a successive grade (Figs. 1, 2). Serpocaulon menisciifolium (clade I) was found to be the sister species to all other species of Serpocaulon. The second clade (clade II) includes $S$. attenuatum and $S$. triseriale. The single sample of $S$. attenuatum is sister to the six samples of $S$. triseriale. All samples of $S$. triseriale share an insertion in the rps4-trnS sequence that is absent in S. attenuatum and all other species of the genus. The next split gives rise to clade III, which is made up of three subclades, IIIa, b and c. Subclade IIIa comprises four samples of $S$. crystalloneuron and one sample each

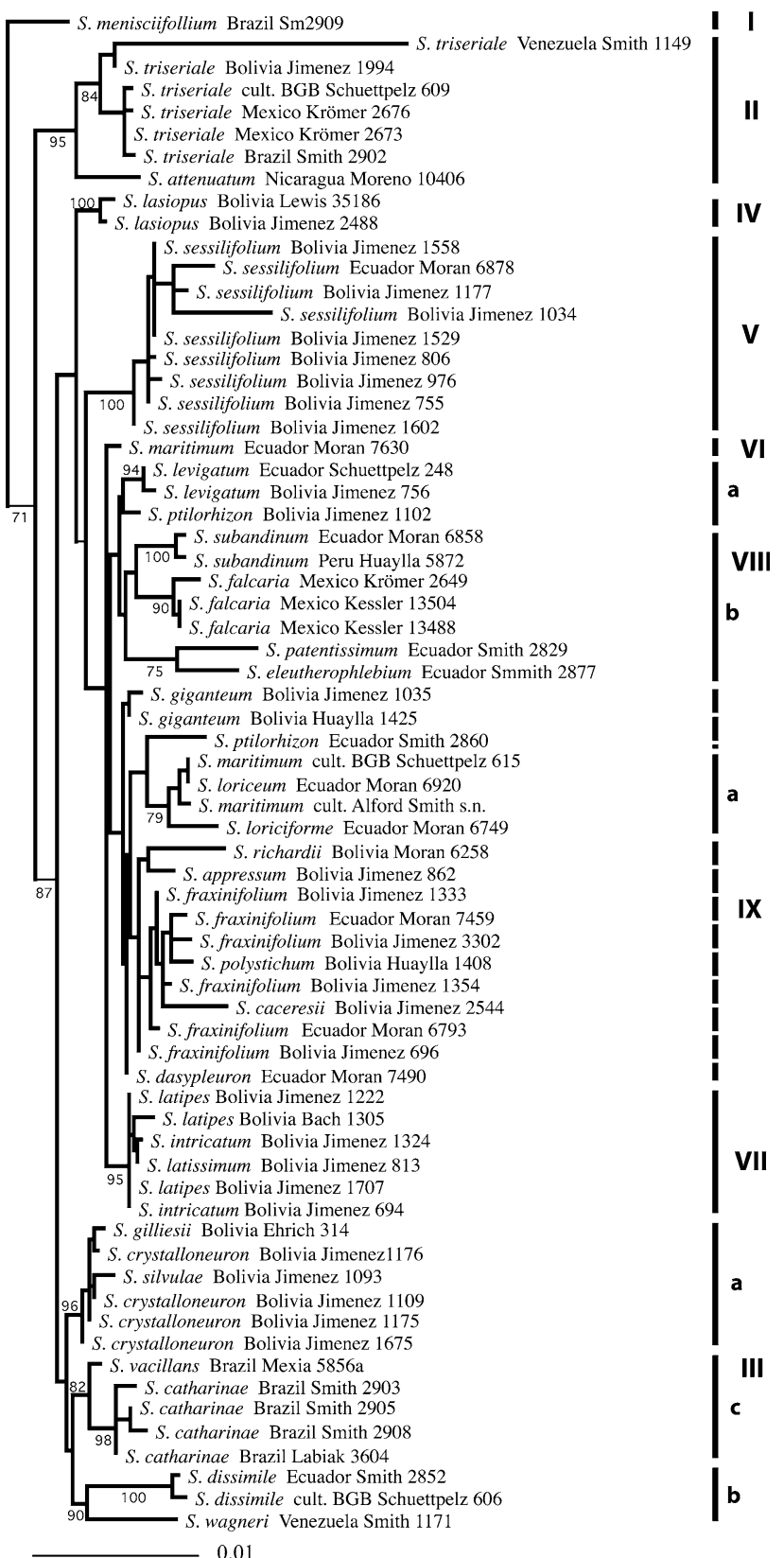

Fig. 1 Phylogram with the highest likelihood value found in the maximum likelihood analysis of the large cpDNA data set. ML bootstrap values $>70 \%$ are given above the branches

of $S$. gilliesii and $S$. silvulae and is characterized by a deletion in the rps4-trnS sequence. Subclade IIIb consists of two samples of $S$. dissimile, which share an insertion in the trnL-F IGS, and one sample of S. wagneri in a sister position. Subclade IIIc comprises four samples of $S$. catharinae as sister to one sample of $S$. vacillans (Fig. 2, clade IIIc). Together, S. catharinae and $S$. vacillans are sister to subclade IIIb comprising $S$. dissimile and $S$. wagneri. The clade combining these two clades is in turn sister to subclade IIIa comprising $S$. crystalloneuron, 


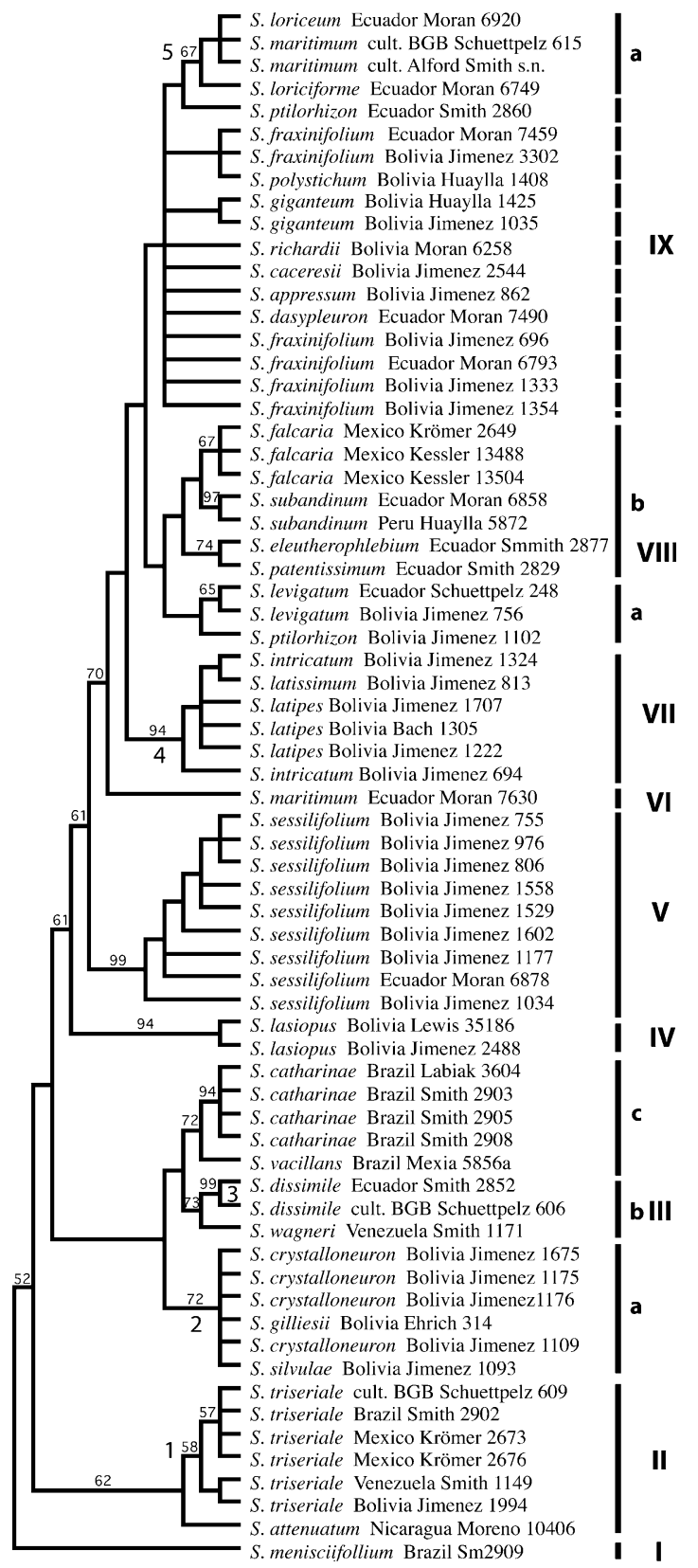

Fig. 2 Strict consensus tree of 21,000 most parsimonious trees obtained in the maximum parsimony analysis of the large cpDNA data set. Bootstrap values $>50 \%$ are given above the branches. Five apomorphic indels are marked on the corresponding nodes: (1) insertion of a GAAGTAGATTCCT motif in the rps4-trnS IGS; (2) deletion of a CTAAAAA motif in the rps4-trnS IGS; (3) insertion of a GAAAAA motif in the $\operatorname{trnL}-\operatorname{trn} \mathrm{F}$ IGS ; (4) deletion of a ATTGGCAAAACG in the rps4-trnS IGS; and (5) deletion of a CAATTGTTGGTATT motif in the rps4-trnS IGS

S. gilliesii and S. silvulae. The next three splits consist of two samples of $S$. lasiopus (clade IV), nine samples of $S$. sessilifolium (clade $\mathrm{V}$ ) and one sample of S. maritimum (clade VI), respectively.
Clade VII (Figs. 1, 2) comprises three samples of $S$. latipes, $S$. intricatum and one sample of $S$. latissimum. All members of this clade share a deletion in the rps4-trnS sequence. The next clade (clade VIII, Figs. 1,2) is again composed of two subclades, which are sister to each other. One of these (subclade VIIIa) includes two samples of $S$. levigatum and one of two samples of S. ptilorhizon, whereas the other one (subclade VIIIb) harbors one sample of $S$. eleutherophlebium, three samples of $S$. falcaria, one sample of $S$. patentissimum and two samples of $S$. subandinum. Within subclade VIIIb, S. falcaria was recovered as sister to $S$. subandinum, and both are sister to a clade containing S. eleutherophlebium and S. patentissimum. The last, only poorly resolved clade IX (Figs. 1, 2) includes one sample each of S. appressum, S. caceresii, S. dasypleuron, S. loriceum, S. loriciforme, S. polystichum, $S$. ptilorhizon, and $S$. richardii, two samples each of $S$. maritimum and $S$. giganteum and six samples of S. fraxinifolium. Within clade IX, Serpocaulon loriciforme is sister to the two samples of S. maritimum and S. loriceum. Together, these samples form subclade IXa that shares a deletion in the rps4-trnS sequence and is sister to an $S$. ptilorhizon sample.

\section{Chloroplast sequences (small data set)}

Maximum parsimony analysis of the small cpDNA data set resulted in 7,516 most parsimonious trees with a length of 255 steps, consistency index of 0.7922 , homoplasy index of 0.2078 , retention index of 0.8140 and a rescaled consistency index of 0.6448. The MP analysis of the small data set found in general the same topology for clades II-V as in the analysis of the large data set, but there are a few notable topological differences (Fig. 3, left panel). Serpocaulon triseriale was chosen as the outgroup in the small data set, because neither non-Serpocaulon species nor S. menisciifolium were included here. Serpocaulon dissimile (clade IIIb in Figs. 1 and 2) is sister to S. catharinae (clade IIIc in Figs. 1 and 2), and this clade is part of a polytomy with $S$. crystalloneuron (clade IIIa in Figs. 1 and 2) and a clade comprising all other samples. Within the latter clade, Serpocaulon sessilifolium (clade V in Fig. 1 and 2) was found to be sister to a clade comprising the remainder of the samples, which together make up clade VI-IX in Figs. 1 and 2. Serpocaulon subandinum (subclade VIIIb in Figs. 1 and 2) was recovered as the sister of the remaining components of this crown group, followed by S. levigatum, making clade VIII paraphyletic in this analysis. The two included samples of clade VII (S. latipes and S. latissimum) cluster together and are sister to $S$. maritimum (clade VI in Figs. 1 and 2). The included samples of clade IX likewise form an unresolved clade. 
Fig. 3 Comparison of strict consensus trees obtained by maximum parsimony analysis of the small cpDNA data set (left panel) and the corresponding AFLP data set (right panel). Bootstrap values $>50 \%$ are given above the branches
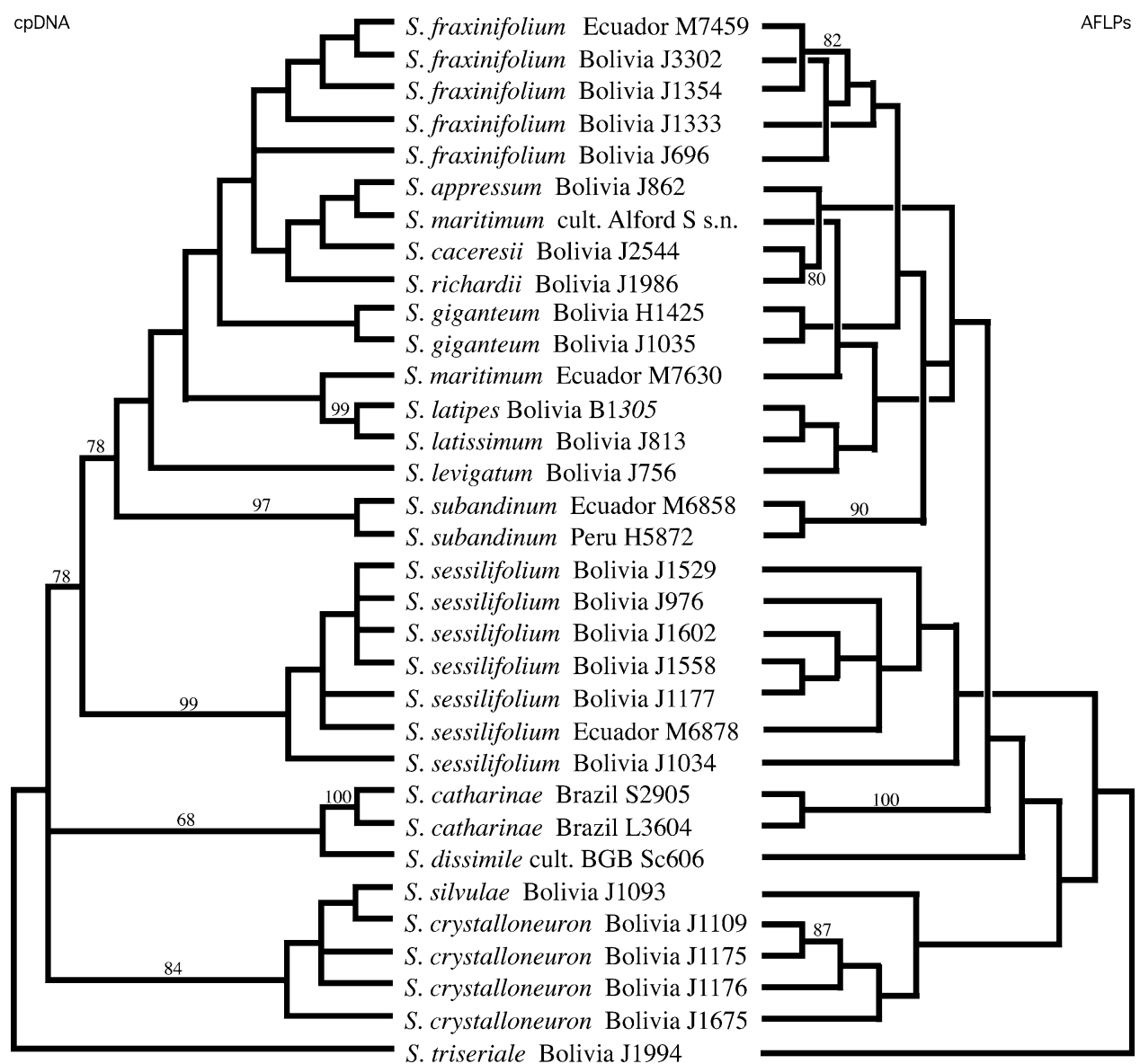

\section{AFLP assays}

Ten combinations of labeled HindIII- and unlabeled MseIprimer with +3 and/or +4 selective bases each were prescreened with a small set of template DNAs. Well-resolved banding patterns were obtained with 10 primer pairs that were eventually retained to analyze the entire set of samples (Table 2). The number of band positions that could be scored unequivocally varied from 7 to 60 , depending on the primer pair (Table 2). A total of 312 band positions were entered into a binary data matrix and analyzed as described in the "Materials and methods" section. Principal component analyses for all ten primer combination found explanation values ranging from 37.89 to 43.6 for the explanation summary of axis 1 plus axis 2 and none of the primer combination appears to especially underperform in comparison to other primers. Maximum parsimony analysis of the AFLP data set resulted in seven most parsimonious trees with a length of 800 steps, consistency index of 0.2812 , homoplasy index of 0.7188 , retention index of 0.4907 and a rescaled consistency index of 0.1380 . In concordance with the results of the cpDNA analyses, Serpocaulon triseriale was assigned as the outgroup taxon
(Fig. 3, right panel). The topology recovered in the MP analyses of the AFLP assays is generally similar, but not identical to the one found in the MP analyses of the chloroplast data (Fig. 3, left panel). One major difference is the position of $S$. sessilifolium (clade V in Figs. 1 and 2), which is sister to all other Serpocaulon species except the outgroup. The AFLP data also support the monophyly of the S. crystalloneuron aggregate (five samples), S. sessilifoium (seven samples), S. subandinum (two samples), S. catharinae (two samples), S. giganteum (two samples) and $S$. fraxinifolium (five samples). The two samples of $S$. maritimum cluster together only in the AFLP tree, but not in the cpDNA tree. Further differences between the phylogenetic reconstructions based on cpDNA versus AFLP evidence mainly concern relationships within monophyletic species aggregates such as $S$. sessilifolium, S. fraxinifolium and $S$. crystalloneuron. Different topologies were also found for relationships within and among clades VII, VIII and IX, and for the deeper relationships in Serpocaulon. Clade IIIb is sister to IIIc and the crown group, making clade III polyphyletic in the AFLP-based analysis. Clade VIII is polyphyletic. Clade VIII and clade VII are nested among clade IX species. As in the cpDNA analysis, 
Fig. 4 Network generated using the

NeighborNet algorithm as implemented in Splitstree, based on a Nei-Li distance matrix derived from the AFLP data set. Dots correspond to the actual position of sampled specimens. Connecting lines indicate possible relationships within the unrooted network. If samples are located in the same area of the network, the actual specimen is replaced with a bended line circumscribing the groupings. Serpocaulon maritimum 1 corresponds with the specimen cult. Alford s.n, whereas $S$. maritimum 2 corresponds with Moran 7630

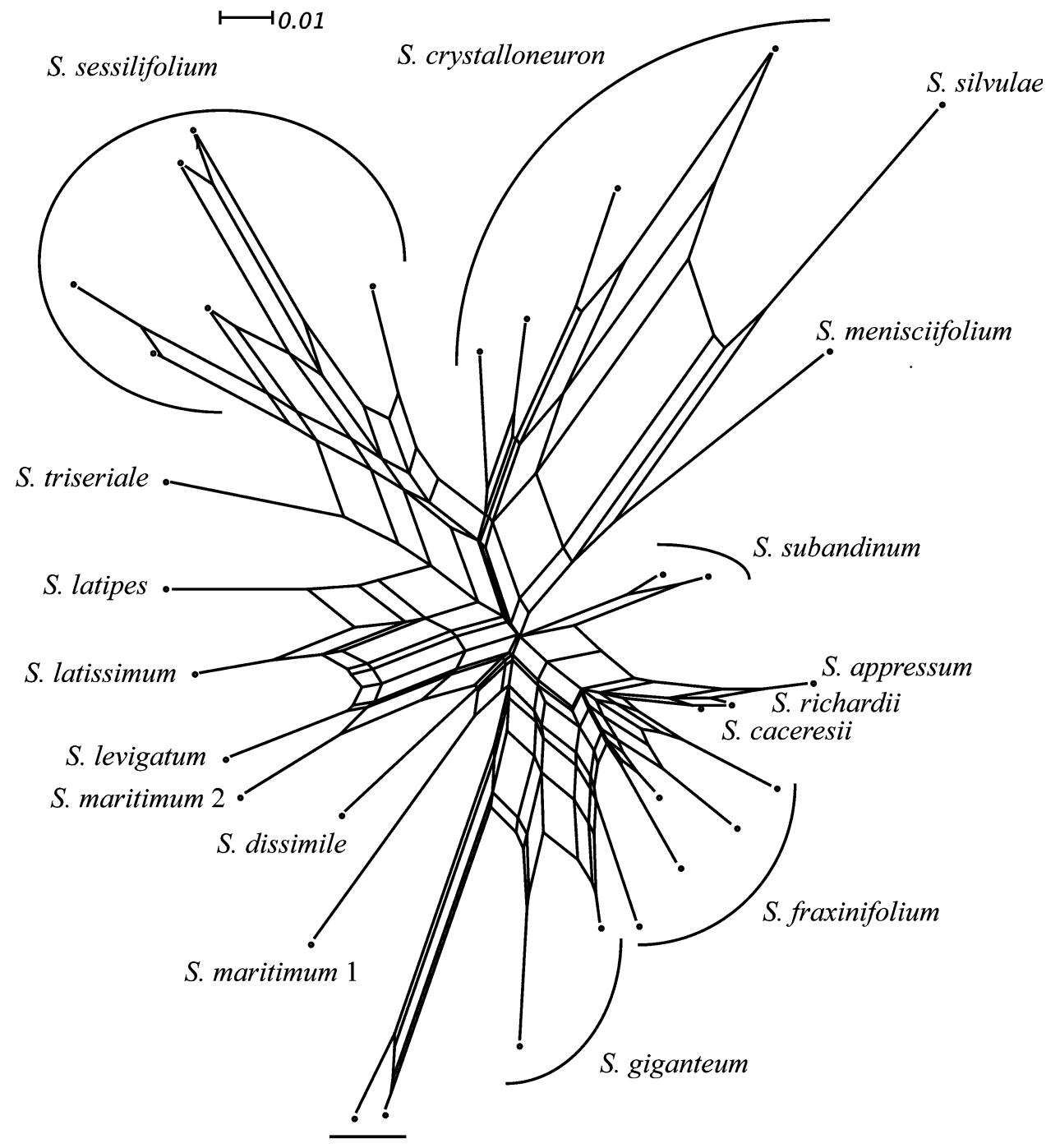

S. catharinae bootstrap support is low for the majority of clades and no support was found for any of the clades that were part of alternative topologies in the cpDNA-based hypothesis.

The NeighborNet analysis based on the banding pattern of the AFLP assays transformed into Nei-Li distances recovered a complex network under the condition of four dimensions (Fig. 4). There are many alternative connections, especially for the deeper relationships $(70 \mathrm{nSplits}$ with a total weight of 1.6412 and a fit of 88.47). There is no evidence for deeper relationships, as the center of the unrooted network collapses more or less to a star-like tree. Species found to form early segregates in the rooted cpDNA cladograms are distributed throughout the network (see, for example, S. catharinae, S. dissimile, and S. triseriale). If two or more specimens of the same species are included, they are found in the same area of the network (except S. maritimum; Fig. 4). One grouping in the network, namely S. latipes, S. latissimum, and S. levigatum, and one of the two specimens of $S$. maritimum correspond to the group reported in the MP analyses. The distance matrix suggests closer relationships among the five samples of $S$. fraxinifolium than for the six samples of $S$. sessilifolium and S. crystalloneuron. Serpocaulon silvulae is related to $S$. crystalloneuron, but not part of the core of the $S$. crystalloneuron subnetwork. The network also suggests close relationships among $S$. fraxinifolium, the two distinct samples of $S$. giganteum and the clan formed by $S$. appressum, S. caceresii and S. richardii. The two samples of $S$. giganteum show a clear differentiation in the AFLP banding pattern, which is also reflected in the distance to each other in the network, despite their side-by-side location (Fig. 4).

\section{Combined AFLP and cpDNA (total evidence analysis)}

The combined MP analysis of the small cpDNA and AFLP data sets found two most parsimonious trees with a length of 1,724 steps and a consistency index of 0.2443 , retention 
index of 0.4851 and a rescaled consistency index of 0.1500 . In general, the strict consensus tree of the two most parsimonious trees is consistent with the results recovered in the independent analyses of the AFLP and cpDNA data sets shown in Fig. 3. However, it lacks resolution among the terminal nodes of the derived clades, where conflicting topologies were found in the independent analyses.

\section{Discussion}

Utility of AFLPs for phylogenetic studies in epiphytic ferns

The relevance of AFLPs in phylogenetic studies is controversial due to the difficulty in assessing homologies and the extent of homoplasy (Koopman et al. 2001; Bussell et al. 2005; Koopman 2005; Simmons et al. 2007). In general, the application of AFLPs should be restricted to intraspecific relationships or to studies involving only closely related species, because the ambiguity of homology assessments increases with the phylogenetic distance among taxa (e.g. Després et al 2003). To date, the largest fern data set analyzed using AFLPs included 14 species (Perrie et al. 2003). Since cpDNA variability was low throughout Serpocaulon, we sampled the core genus, except for some basal clades, e.g. S. triseriale clade. To avoid increased ambiguity, we restricted the AFLP data set to Serpocaulon and selected $S$. triseriale as the outgroup taxon, because cpDNA trees showed that this species is a member of one of the basal clades in the genus. The large phylogenetic distances discovered in the cpDNA data set contraindicates the inclusion of species from other genera of Polypodiaceae in the AFLP study.

The network obtained in the split graph analyses underlined the utility of AFLP assays to identify genetic disparity within species, but with the price of limiting the ability to determine the relationships among species. Accumulation of AFLP-band polymorphism may cause positively misleading reconstructions in distance-based phylogenetic approaches, as the result of an increasing imbalance between short branches connecting deeper branches in the phylogram and longer branches leading to the terminal taxa. Our data suggest that AFLP assays more accurately predict relationships if several specimens are sampled for each species. The denser sampling strategy may overcome distortion introduced by plesiomorphic AFLP-band polymorphisms. However, it is unclear if a denser sampling strategy may be able to elucidate deep relationships within the Serpocaulon clade without constraining the analyses according to the results of the cpDNA analyses. Our current sampling is insufficient to explore fully the advantages of network analyses over analyses relying on bifurcating dendrograms. Network analyses, however, may potentially be a powerful approach for inferring complex markers such as AFLPs.

In general, the AFLP analysis found the same principal groups as the cpDNA analysis, including the multiply sampled species, S. crystalloneuron and S. sessilifolium. However, AFLPs appear to recover deeper relationships less reliably, as especially illustrated in the network analyses (Fig. 4). Consequently, we performed a combined analysis based on AFLP banding patterns, cpDNA sequences, and putatively apomorphic indels in the cpDNA sequence data. This total evidence analysis did not improve resolution (not shown), which may be due to the heterogeneity of the data sets. The low bootstrap support for basal nodes in independent MP analyses of the two data sets, but especially for the AFLP assays, enables testing for topological heterogeneity. A path not taken was the reconstruction of a super tree, although this approach may offer a powerful tool to generate consensus hypotheses under the assumption of conflicting signals as the result of different inheritance of some informative characters.

Within the densely sampled and monophyletic $S$. crystalloneuron and S. sessilifolium clades, AFLP and cpDNA analyses yielded conflicting topologies. These conflicts may be the result of homoplasy or an indication of recombination. The inheritance of plastid markers and AFLPs is not necessarily identical, because cpDNA is inherited uniparentally in ferns (Gastony and Yatskievych 1992; Vogel et al. 1998), whereas the majority of AFLP bands are most probably inherited in a biparental fashion (Bussell et al. 2005). AFLPs and cpDNA sequence data differ somewhat in the suggested relationship of $S$. maritimum (Moran 7630, Alford s.n.) and S. levigatum (Jimenez 756). The two samples of $S$. maritimum are sister in the AFLP analyses, but not in the cpDNA analyses. The different inheritance modes for cpDNA sequences versus AFLP bands may indicate introgression and/or hybridization in these epiphytic ferns.

\section{Taxonomic implications}

Hensen (1990) wrote the most current revision of Serpocaulon, recognizing this genus as the Polypodium loriceum group. Since then, several new species have been described (see Smith et al. 2006), and some taxonomists have expressed doubts on currently existing species concepts of several widespread species (Smith et al. 2006). Our study provides suggestions for a much-needed revision of this genus. The combination of cpDNA and AFLP markers may prove to be a powerful tool to reconstruct phylogenetic relationships on which species recognition could be based. We suggest that other markers, such as sequences of highly variable nuclear DNA loci, be considered as additional 
evidence. The cpDNA molecule is usually uniparentally inherited and thus cannot be used to detect introgression and hybridization. AFLP assays combine information from both parents, but suffer to some extent from ambiguous homology assessment. A combination of both is one strategy to determine introgression and hybridization; however, it is important to keep in mind that AFLPs are, in general, dominant markers.

Our data support the separation of $S$. attenuatum from $S$. triseriale by the lack of an indel occurring in all six samples of $S$. triseriale. Our current sampling of $S$. triseriale covers most of its distribution range, suggesting that our result is not a sampling artifact; however, only a single specimen of $S$. attenuatum was sampled. Information on the nuclear genome for these taxa would allow us to make more explicit statements about the taxonomic status of $S$. attenuatum.

Two species with restricted geographic distributions, $S$. gilliesii and S. silvulae, are part of a clade that also includes $S$. crystalloneuron in the cpDNA-based analyses. This result illustrates that species boundaries in this group should be re-examined. The AFLP data suggest $S$. silvulae is sister to $S$. crystalloneuron, and the different topologies based on cpDNA and AFLP data may be explained by the lack of cpDNA variation or be taken as evidence for recombination. In either case, the status of $S$. silvulae and $S$. gilliesii requires attention. The cpDNA data reveal a similar pattern in the $S$. latipes clade, in which S. latissimum and $S$. intricatum are nested. Neither of the two samples of $S$. intricatum nor the three samples of $S$. latipes form a monophylum in our analysis.

The majority of taxonomic problems are found in clades XIII and IV. The recently resurrected species S. polystichum is nested within the clade comprising samples of $S$. fraxinifolium collected in Bolivia and Ecuador. The two samples of $S$. giganteum form a monophylum and are separate from $S$. fraxinifolium using either cpDNA or AFLPs. Distancebased analyses of the AFLP assays provided evidence for a strong differentiation between the two samples of $S$. giganteum and close relationships of both to $S$. fraxinifolium, especially for Huaylla 1425. Both species were treated as synonyms of $S$. fraxinifolium by Hensen (1990) but not by Smith et al. (2006). Another interesting problem is the identity of $S$. maritimum. cpDNA did not adduce evidence for this taxon as monophyletic, whereas the two samples included in the AFLP data set form a monophylum. These results indicate that the current concept of $S$. maritimum needs re-examination. Serpocaulon sessilifolium was recovered as monophyletic in both cpDNA and AFLP analyses, but all samples came from the central Andes, while the currently accepted range extends into Central America and the Caribbean. The monophyly of S. dissimile, S. lasiopus, S. levigatum and S. subandinum was supported in our analyses, but only samples from central South America were examined; all of these species have ranges extending further northward. Serpocaulon catharinae and $S$. falcaria both have limited distribution ranges, for which our sampling may be sufficiently representative: their status as species was supported. It was not our objective to resolve issues concerning the status of several species, but the present data suggest the need for more exhaustive studies on the taxonomy of this genus. Our study also draws attention to the need for studies on speciation processes and on the extent of hybridization and introgression in tropical epiphytic ferns as such (Haufler et al. 2000; Haufler 2002). Currently, only a single putative hybrid has so far been identified in Serpocaulon (Moran 1990; Tryon and Stolze 1993). This hybrid, S. semipinnatifidum (Fée) A. R. Sm., has the only simple-bladed species in the genus, S. levigatum, as one parent (Moran 1990; Tryon and Stolze 1993). The hybrid is therefore relatively easily detected based on the intermediate morphotype of the lamina.

\section{Historical biogeography}

In Smith et al. (2006), the hypothesis was presented that Serpocaulon arose from species growing primarily in lowland to mid-elevation rainforests of South and Central America. Derived species of this genus, however, occur predominantly in the Andean rainforests at higher elevations. Our expanded taxon sampling gives further evidence supporting this hypothesis, but also suggests a more explicit scenario concerning the ancestral distribution range of the Serpocaulon lineage and the migration path that allowed these ferns to colonize the mid- to high-elevation Andean mountain forests (Fig. 5). Several species nested in the basal clades (clades I-III) occur exclusively in southeastern Brazil (e.g. S. catharinae, S. menisciifolium, S. vacillans). Other members of clades I-III are more broadly distributed, e.g., S. triseriale ranging from Bolivia to southern Mexico and the Caribbean, and $S$. dissimile from Ecuador to southern Mexico and the Caribbean. All of these taxa occur preferentially at elevations between 500 and 1,200 m. Among clades I-III, S. crystalloneuron and relatives are the only taxa with a preference for higher elevations (mainly 2,400-3,750 m), with $S$. gilliesii descending down to $950 \mathrm{~m}$ in southern Bolivia. The nearly exclusive occurrence of this lineage in Bolivia suggests an origin of the core Serpocaulon clade in the Bolivian Andes. On the contrary, the AFLP data (Fig. 3) suggest (though without bootstrap support) that S. sessilifolium (Fig. 2, clade $\mathrm{V}$ ), which is not only common in Bolivia but also in Ecuador, Peru, Colombia, Venezuela, as well as Mesoamerica, is sister to the remainder of the genus. Thus, available evidence does not allow identifying the area of origin of this widespread species. Its current distribution 


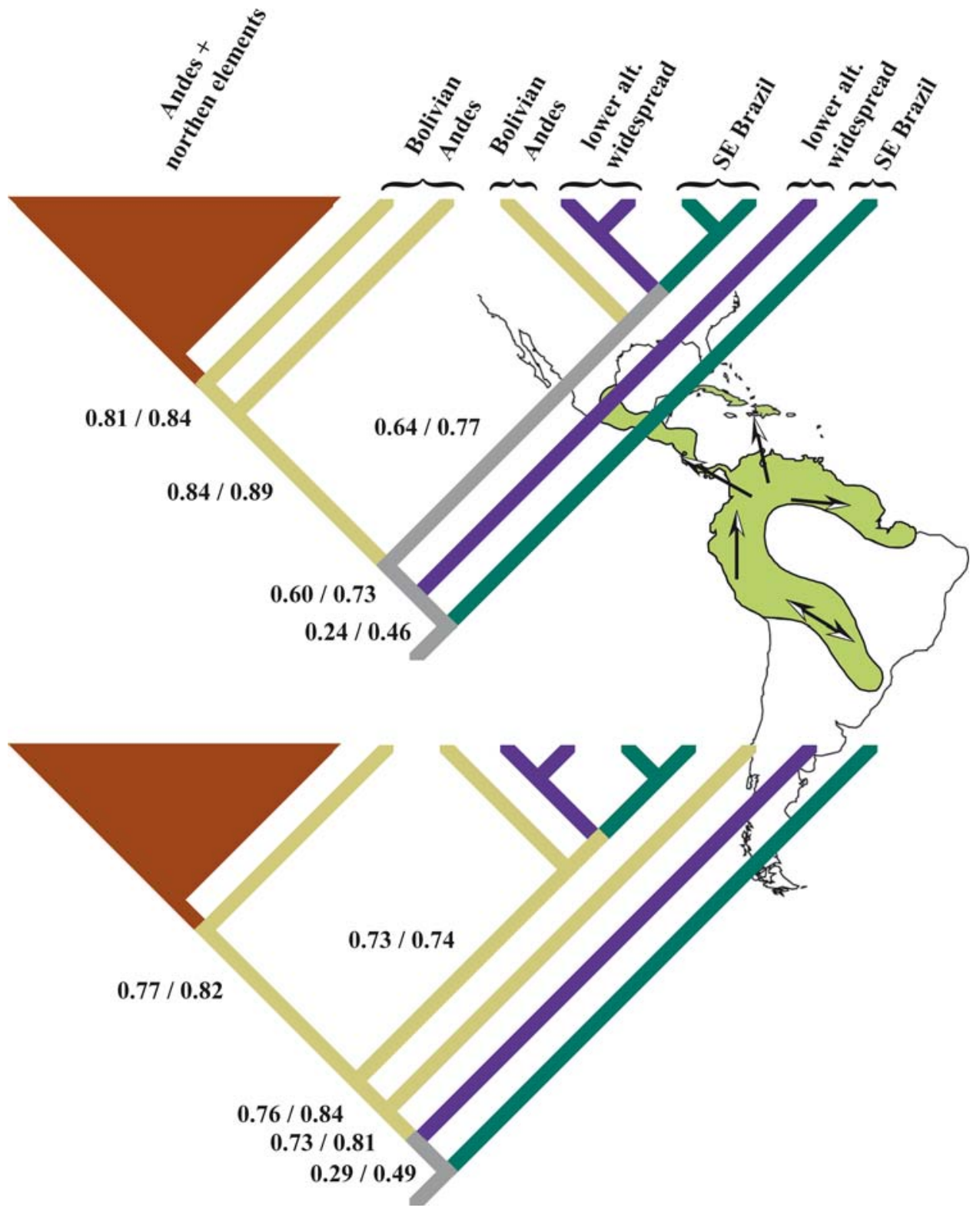

Fig. 5 Reconstruction of the historical biogeographic scenario based on the obtained results. The phylogenetic hypothesis shown in the upper panel is based on the cpDNA evidence, whereas the lower one is based on the AFLP assays. The map of South America shows the core distribution of Serpocaulon (green/gray area), with the arrows illustrating the major migration routes. Color/gray scale of branches corresponds to the maximum parsimony reconstruction of ancestral character states with ACCTRAN and DELTRAN optimization: blue/ dark gray $=$ widespread lowlands, green/dark gray = southeastern Brazil, gray/medium gray $=$ unresolved, red/dark gray $=$ Andes and northern distribution, and yellow/bright gray $=$ Bolivian Andes. The given color code correspond to the color version available online whereas the gray scale correspond to the printed version. The red/ dark gray triangle includes the core of Serpocaulon species diversity

may be the result of a range expansion of which occurred in parallel to and independent of the range expansion proposed for the core of Serpocaulon. Thus, this alternative topology based on AFLPs does not necessarily contradict
( $>70 \%)$. Numbers below or above the branches correspond to the likelihood values for Bolivian Andes/Bolivian Andes + southeastern Brazil as the ancestral distribution range for the particular node. To obtain phylogenetic-based hypotheses on ancestral distribution, the ranges were scored for each terminal taxon as one of four states: (1) Brazil, (2) widespread lowland, (3) Bolivian Andes, and (4) Andes and northern areas. To avoid ambiguity, we interpreted the occasional occurrence of some species in other areas as their main distribution as the result of secondary dispersal. This is particularly in the case of $S$. sessilifolium, which occurs from Bolivia to Mesoamericana. Its more widespread distribution is assumed as the result of an expansion of the species range in parallel to the proposed expansion of the distribution range of the core Serpocaulon clade

the scenario suggested by the cpDNA-based topology (Fig. 5).

This biogeographic pattern points to the Bolivian Andes as the distribution range of the common ancestor of clades 
VI-IX. The descendents of this ancestor then extended their ecological and geographical range through the central and northern Andes to Central America. Only a single species nested in clades VI-IX occurs exclusively outside the Andes, namely S. falcaria from southern Mexico to Honduras. Several species in these clades occur exclusively or at least predominantly in the Andes, e.g. S. appressum, S. dasypleuron, S. eleutherophlebium, S. intricatum, S. latissimum, $S$. patentissimum, $S$. subandinum, and $S$. richardii. Others, however, have much larger distributions extending to Brazil, southern Mexico, and/or the Caribbean, e.g. S. caceresii, S. fraxinifolium, S. giganteum, S. levigatum, S. loriceum, S. loriciforme, S. maritimum and $S$. ptilorhizon. Despite their geographical distance of about $1,500 \mathrm{~km}$, the Bolivian Andes have a geographical connection to southeastern Brazil via relictual mountain ranges in central Brazil and eastern Bolivia. These mountains were formerly more extensive and may have served as stepping stones for a number of plant and animal taxa moving both from the Andes to southeastern Brazil and vice versa (Silva 1995; Windisch and Tryon 2001). In the context of our discussion of the diversification of Serpocaulon, of particular interest are species or species pairs from a wide range of taxa that are widespread in southeastern Brazil (and sometimes central Brazil) and have small, isolated populations in the Bolivian Andes without extending further north in the Andes. Examples include the ferns Serpocaulon vacillans, Anemia buniifolia (Gardner) T. Moore (Anemiaceae) and Thelypteris decurtata (Link) de la Sota subsp. decurtata (Thelypteridaceae), the epiphytic cactus Rhipsalis cereuscula Haw. (Ibisch et al. 2000), and various birds, e.g. Phibalura flavirostris Viellot and P. boliviana (Chapman) (Hennessey 2002). These disparate species do not occur at the same localities in the Bolivian Andes, but all are found at elevations of 800 $1,800 \mathrm{~m}$, mostly in semi-humid, seasonal habitats. These habitat conditions correspond to those found in southeastern Brazil and especially mountains in central Brazil. Although phylogeographic analyses are so far lacking, taken together these examples suggest repeated and fairly recent dispersal from southeastern Brazil to Bolivia without subsequent ecological differentiation and range expansion in the Andes. It is conceivable that early members of Serpocaulon similarly colonized Bolivia from Brazil and adapted to high-elevation habitats not present in southeastern Brazil before expanding their ranges northwards. The reverse migration from Bolivia to southeastern Brazil is also likely since strong wind currents blow from the Andes eastwards.

The Bolivian-southeastern Brazilian cradle hypothesis is interesting with respect to previously suggested hypotheses about the biogeographic history of South American ferns. Tryon (1972) proposed three primary regional centers of neotropical ferns, including an Andean region and a southeastern Brazilian region. In our hypothesis, the Bolivian Andes and adjacent southeastern Brazil are together the putative ancestral home of Serpocaulon, whereas the Bolivian Andes formed the steppingstone for migration and successful colonization of the more northern Andean areas; subsequent migration ensued into Central America and the Caribbean. Tryon (1971) suggested a similar migratory track for the genus Doryopteris J. Sm., whereas a more complex scenario was hypothesized for Jamesonia/Eriosorus by Sánchez-Baracaldo (2004). She proposed that this lineage originated in Brazil and colonized the Andes, possibly through long-distance dispersal in two separate episodes, one to the central Andes and another to the northern Andes. The first track of Andean colonization is similar to the one suggested here for Serpocaulon. The reverse route, migrating from an ancestral source in central or northern America into the Andes, has been proposed for other genera: Gentianella Moench (von Hagen and Kadereit 2001), Halenia Borkh. (von Hagen and Kadereit 2003), Lupinus L. (Hughes and Eastwood 2006) and Valeriana L. (Bell and Donoghue 2005). For most Andean plant taxa, centers of diversification are located in Colombia, Ecuador and Peru, but a number of taxa adapted to seasonally dry habitats have their centers of diversity in Bolivia (Krapovickas and Gregory 1994; López 2003).

The role of Bolivia as a center of plant diversification has not received much attention to date, but the case of Serpocaulon, Doryopteris and the angiosperm genera listed above suggest that Bolivia's location, the transition fom the climatically largely aseasonal inner tropics to the seasonal subtropics, may have provided opportunities for the diversification of taxa growing in the transition zone between humid and semi-humid habitats.

\section{Conclusions}

Although this study has improved our understanding of Serpocaulon phylogeny, denser sampling is required to sustain the biogeographic hypothesis outlined above. More exhaustive sampling of markers as AFLPs or highly variable nuclear DNA sequences may uncover more details required to generate a plausible scenario for the colonization of the Andes and the subsequent adaptive radiation of the genus in the newly accessible biomes. This study found evidence for a role of the Bolivian-Brazilian region as a cradle (area of origin) for the Andean diversity of Serpocaulon. We hope that this study will inspire additional searches for evidence supporting or rejecting the BolivianBrazilian region as a major center of origin for the overwhelming diversity of plants in the Andes. 
Acknowledgments We thank Charles Alford, Iván Jiménez, Thorsten Krömer and Robbin Moran for providing samples for this study and Tom Ranker for his suggestions. This research was supported by the Deutsche Forschungsgemeinschaft (SCHN 758/2-1 and 758/2-2) under the Schwerpunktprogramm SPP 1127 "Adaptive RadiationsOrigin of Biological Diversity".

Open Access This article is distributed under the terms of the Creative Commons Attribution Noncommercial License which permits any noncommercial use, distribution, and reproduction in any medium, provided the original author(s) and source are credited.

\section{References}

Bell CD, Donoghue MJ (2005) Phylogeny and biogeography of Valerianaceae (Dipsacales) with special reference to the South American valerians. Org Divers Evol 5:147-159

Bryant D, Moulton V (2002) NeighborNet: an agglomerative method for the construction of planar phylogenetic networks. In: Guigó R, Gusfield D (eds) Algorithms in bioinformatics, WABI 2002, vol LNCS 2452, pp 375-391

Bussell JD, Waycott M, Chappill JA (2005) Arbitrarily amplified DNA markers as characters for phylogenetic inference. Persp Pl Ecol Evol Syst 7:3-26

Cuatrecasas J (1986) Speciation and radiation in the Espeletiinae in the Andes. In: Vuilleumier F, Monasterio M (eds) High altitude tropical biogeography. Oxford University Press, New York, pp 267-303

Debener T, Mattiesch L (1999) Construction of a genetic linkage map for roses using RAPD and AFLP markers. Theor Appl Genet 99:891-899

Després L, Gielly L, Redoutet B, Taberlet P (2003) Using AFLP to resolve phylogenetic relationships in a morphologically diversified plant species complex when nuclear and chloroplast sequences fail to reveal variability. Molec Phylogenet Evol 27:185-196

Gastony GJ, Yatskievych G (1992) Maternal inheritance of the chloroplast and mitochondrial genomes in cheilanthoid ferns. Amer J Bot 79:716-722

Haufler CH (2002) Homospory 2002: an odyssey of progress in pteridophyte genetics and evolutionary biology. BioScience 52:1081-1093

Haufler CH, Ranker TA (1995) $r b c \mathrm{~L}$ sequences provide phylogenetic insights among sister species of the fern genus Polypodium. Amer Fern J 85:361-374

Haufler CH, Hooper EA, Therrien JP (2000) Modes and mechanisms of speciation in pteridophytes: implications of contrasting patterns in ferns representing temperate and tropical habitats. Pl Spec Biol 15:223-236

Haufler CH, Grammer WA, Hennipman E, Ranker TA, Smith AR, Schneider H (2003) Systematics of the ant-fern genus Lecanopteris (Polypodiaceae): testing phylogenetic hypotheses with DNA sequences. Syst Bot 28:217-227

Hennessey AB (2002) First Bolivian observation of swallow-tailed Cotinga Phibalura flavirostris boliviana in 98 years. Cotinga 17:54-55

Hensen RV (1990) Revision of the Polypodium loriceum complex (Filicales, Polypodiaceae). Nova Hedw 50:279-336

Hodkinson TR, Renvoize SA, Ni Chonghaile G, Stapleton CMA, Chase MW (2000) A comparison of ITS nuclear rDNA sequence data and AFLP markers for phylogenetic studies in Phyllostachys (Bambusoideae, Poaceae). J Pl Res 113:259-269
Hughes C, Eastwood R (2006) Island radiation on a continental scale: exceptional rates of plant diversification after uplift of the Andes. Proc Natl Acad Sci USA 103:10334-10339

Huson DH, Bryant D (2006) Application of phylogenetic networks in evolutionary studies. Molec Biol Evol 23:254-267

Janssen T, Schneider H (2005) Exploring the evolution of humus collecting leaves in drynarioid ferns (Polypodiaceae, Polypodiidae). Pl Syst Evol 252:175-197

Kang M, Pan L, Yao S, Huang H (2006) Development and characterization of polymorphic microsatellite loci in endangered fern Adiantum reniforme var. sinense. Conserv Genet 7:807-810

Keiper FJ, McConchie R (2000) An analysis of genetic variation in natural populations of Sticherus flabellatus (R. Br.) St John using amplified fragment length polymorphism (AFLP) markers. Molec Ecol 9:571-581

Koopman WJM, Zevenbergen MJ, van den Berg RG (2001) Species relationships in Lactuca s.l. (Lactucaeae, Asteraceae) inferred from AFLP fingerprints. Amer J Bot 88:1881-1887

Koopman WJM (2005) Phylogenetic signal in AFLP data sets. Syst Biol 54:197-217

Krapovickas A, Gregory WC (1994) Taxonomía del género Arachis (Leguminosae). Bonplandia 7:1-186

Kreier H-P, Schneider H (2006) Phylogeny and biogeography of the staghorn fern genus Platycerium (Polypodiaceae, Polypodiidae). Amer J Bot 93:217-225

León B (1992) A taxonomic revision of the fern genus Campyloneurum (Polypodiaceae). PhD thesis, Afdeling für Systematik Botanik, Biologisk Institut, Aarhus Universitet, Denmark

López RP (2003) Phytogeographical relations of the Andean dry valleys of Bolivia. J Biogeogr 30:1659-1668

Luteyn JL (1999) Páramos: a checklist of plant diversity, geographical distribution, and botanical literature. Mem New York Bot Gard 84:1-278

Maddison DR, Maddison EP (2000) MacClade 4.0: analyses of phylogeny and character evolution. Sinauer Associates Inc., Sunderland

Maddison DR, Maddison EP (2004) Mesquite: a molecular system of evolutionary analyses. Version 1.0. http://mesquiteproject.org

Monasterio M, Sarmiento L (1991) Adaptive radiation of Espeletia in the cold Andean tropics. Trends Ecol Evol 6:387-391

Moran R (1990) Review of "Revision of the Polypodium loriceum complex (Filicales, Polypodiaceae)", by Raymond V. Hensen. Amer Fern J 80:118-119

Myers N, Mittermeier RA, Mittermeier CG, da Fonseca GAB, Kent J (2000) Biodiversity hotspots for conservation priorities. Nature 403:853-858

Pelser PB, Gravendeel B, van der Meijeden R (2003) Phylogeny reconstruction in the gap between too little and too much divergence: the closest relatives of Senecio jacobaea (Asteraceae) according to DNA sequences and AFLPs. Molec Phylogenet Evol 9:613-628

Perrie LR, Brownsey PJ, Lockhart PJ, Brown EA, Large MF (2003) Biogeography of temperate Australasian Polystichum ferns as inferred from chloroplast sequence and AFLP. J Biogeogr 30:1729-1736

Perrie LR, Brownsey PJ (2005) Genetic variation is not concordant with morphological variation in the fern Asplenium hookerianum sensu lato (Aspleniaceae). Amer J Bot 92:1559-1564

Posada D, Crandall KA (1998) MODELTEST: testing the model of DNA substitution. Bioinformatics 14:817-818

Pryor KV, Young JE, Rumsey FJ, Edwards KJ, Bruford MW, Rogers HJ (2001) Diversity, genetic structure and evidence of outcrossing in British populations of the rock fern Adiantum capillusveneris using microsatellites. Molec Ecol 10:1881-1894 
Rauscher JT (2002) Molecular phylogenetics of the Espeletia complex (Asteraceae): Evidence from nrDNA ITS sequences on the closest relatives of an Andean adaptive radiation. Amer J Bot 89:1074-1084

Rex M, Patzolt K, Schulte K, Zizka G, Vasquez R, Ibisch PL, Weising K (2007) AFLP analysis of genetic relationships in the genus Fosterella L.B.Smith (Pitcairnioideae, Bromeliaceae). Genome 50:90-105

Sambrook J, Russell DW (2001) Molecular cloning. A laboratory manual, 3rd edn. Cold Spring Harbor Laboratory Press, Cold Spring Harbor

Sánchez-Baracaldo P (2004) Phylogenetics and biogeography of the neotropical fern genera Jamesonia and Eriosorus (Pteridaceae). Amer J Bot 91:274-284

Schneider H, Smith AR, Cranfill R, Haufler CH, Ranker TA, Hildebrand T (2002) Gymnogrammitis dareiformis is a polygrammoid fern (Polypodiaceae)—resolving an apparent conflict between morphological and molecular data. Pl Syst Evol 234:121-136

Schneider H, Janssen T, Hovenkamp P, Smith AR, Cranfill R, Haufler $\mathrm{CH}$, Ranker TA (2004a) Phylogenetic relationships of the enigmatic Malesian fern Thylacopteris (Polypodiaceae, Polypodiidae). Int J Pl Sci 165:1077-1087

Schneider H, Smith AR, Cranfill R, Hildebrand TE, Haufler CH, Ranker TA (2004b) Unraveling the phylogeny of polygrammoid ferns (Polypodiaceae and Grammitidaceae): exploring aspects of the diversification of epiphytic plants. Molec Phylogenet Evol 31:1041-1063

Silva JMC (1995) Biogeographic analysis of the South American cerrado avifauna. Steentrupia 21:49-67

Simmons MP, Zhang L-B, Webb CT, Mueller K (2007) A penalty of using anonymous dominant markers (AFLPs, ISSRs, and RAPDs) for phylogenetic inference. Molec Phylogenet Evol 42:528-542

Smith JMB, Cleef AM (1988) Composition and origins of the world's tropical alpine floras. J Biogeogr 15:631-645

Smith AR, Kreier H-P, Haufler CH, Ranker TA, Schneider H (2006) Serpocaulon (Polypodiaceae), a new genus segregated from Polypodium. Taxon 55:919-930

Squirrell J, Woodhead M, Hollingsworth PM, Russell J, Gibby M, Powell W (2004) Isolation of polymorphic microsatellite markers for the Alpine lady fern, Athyrium distentifolium Tausch ex Opiz, from an enriched genomic library. Conserv Genet 5:283286

Swofford DL (2000) PAUP*: phylogenetic analysis using parsimony (* and other methods), version 4. Sinauer Associates Inc., Sunderland

Tryon RM (1971) Ferns of the Andes and Amazon. Morris Arbor Univ Pensyl Bull 22:7-13
Tryon RM (1972) Endemic areas and geographic speciation in tropical American ferns. Biotropica 4:121-131

Tryon RM (1985) Fern speciation and biogeography. Proc Roy Soc Edinburgh 86B:353-360

Tryon RM (1986) The biogeography of species, with special reference to ferns. Bot Rev 52:117-156

Tryon RM, Stolze RG (1993) Pteridophyta of Peru, Part V. 18. Aspleniaceae - 21. Polypodiaceae. Fieldiana Bot 32:1-190

Vitalis R, Dubois M-P, Olivieri I (2001) Characterization of microsatellite loci in the endangered species of fern Marsilea strigosa Willd. (Marsileaceae, Pteridophyta). Molec Ecol Notes 1:64-66

Vitalis R, Riba M, Colas B, Grillas P, Olivieri I (2002) Multilocus genetic structure at contrasted spatial scales of the endangered water fern Marsilea strigosa Willd. (Marsileaceae, Pteridophyta). Amer J Bot 89:1142-1155

Vogel JC, Russell SJ, Rumsey FJ, Barrett JA, Gibby M (1998) Evidence for maternal transmission of chloroplast DNA in the genus Asplenium (Aspleniaceae, Pteridophyta). Bot Acta 111:247-249

von Hagen KB, Kadereit JW (2001) The phylogeny of Gentianella (Gentianaceae) and its colonization of the southern hemisphere as revealed by nuclear and chloroplast DNA sequence variation. Org Divers Evol 1:61-79

von Hagen KB, Kadereit JW (2003) The diversification of Halenia (Gentianacae): ecological opportunity versus key innovation. Evolution 57:2507-2518

Vuilleumier F (1970) Insular biogeography in continental regions, 1. Northern Andes of South America. Amer Naturalist 104:373-388

Windisch PG, Tryon RM (2001) The Serra Ricardo Franco (State of Mato Grosso, Brazil) as probable migration route and its present fern flora. Bradea 8:265-276

Wikström N, Kenrick P, Chase M (1999) Epiphytism and terrestrialization in tropical Huperzia. Pl Syst Evol 218:221-243

Woodhead M, Russell J, Squirrel J, Hollingsworth PM, Mackenzie K, Gibby M, Powell W (2005) Comparative analysis of population genetic structure in Athyrium distentifolium (Pteridophyta) using AFLPs and SSRs from anonymous and transcribed gene regions. Molec Ecol 14:1681-1695

Zhang L-B, Comes HP, Kadereit JW (2001) Phylogeny and quaternary history of the European montane/alpine endemic Soldanella (Primulaceae) based on ITS and AFLP variation. Amer J Bot 88:2331-2345

Zwickl DJ (2006) Genetic algorithm approaches for the phylogenetic analysis of large biological sequence data sets under the maximum likelihood criterion. Ph.D. dissertation, University of Texas at Austin, Austin 